\title{
Adoption of Open Source in the Software Industry
}

\author{
Øyvind Hauge, Carl-Fredrik Sørensen, and Reidar Conradi \\ Norwegian University of Science and Technology \\ \{oyvind.hauge|carl.fredrik.sorensen|reidar.conradi\}@idi.ntnu.no
}

\begin{abstract}
Is Open Source Software (OSS) undergoing a transformation to a more commercially viable form? We have performed a survey to investigate the adoption of OSS in the Norwegian software industry. The survey was based on an extensive screening of software companies, with more than 700 responses. The survey results support the transformation predicted by Fitzgerald [4]. Close to $50 \%$ of the software industry integrate OSS components into vertical solutions serving all major business sectors. In addition, more than $30 \%$ of the 95 respondents in our survey have more than $40 \%$ of their income from OSS related services or software. The extensive adoption of OSS in the software industry may be a precursor of the OSS adoption in other business sectors.
\end{abstract}

\section{Introduction}

Open source software (OSS) is predicted to transform "into a more mainstream and commercially viable form" [4], where companies play an increasingly more important role. A premise for this transformation is increased commercial participation in the development of OSS products and increased use of OSS in vertical domains. However, only a few surveys provide empirical findings which support this assumed transformation, and most of these focus on the use of desktop tools and horizontal infrastructures like the LAMP stack. Is really OSS undergoing a transformation?

To answer this question we have performed a large scale survey in the Norwegian software industry. Our analysis shows that close to $50 \%$ of the software industry integrate OSS components into vertical solutions targeting customers from all major business sectors. In addition, more than $30 \%$ of the respondents in our survey have more than $40 \%$ of their income from OSS related services or software.

Our results show that the adoption of OSS in the Norwegian software industry is significant. The industry's contribution to the OSS community is however limited. Nevertheless, it is reason to believe that OSS is actually undergoing a transformation into a more commercially viable form. The use of OSS in the software industry may eventually influence the rest of the market when software companies integrate OSS into their products. However, a lack of software companies adopting OSS may hamper the adoption of OSS in other sectors [15]. 


\section{Related Work}

Estimating the market share of OSS is a comprehensive task. Nevertheless, several attempts have been made e.g. [5, 6, and 18]. Common to most of these is their focus on a few products like the LAMP stack and end-user applications like mail or office tools. One example is the Netcraft ${ }^{1}$ survey of web servers on the Internet. While several consultancy companies have attempted to estimate the adoption of OSS, we rather focus on research published through academic channels.

Without providing any numbers, Glynn et al. conclude that OSS has had significant penetration in the software/consultancy and service/communication sector, but that it is more limited in the government/public sector [7]. Studies from the UK [17], Finland [15], and the U.S. [16] report only limited OSS adoption in the public sector with Linux as the only exception. Linux was used by more than $50 \%$ of the respondents in both the study from Finland and the U.S. Together with the other elements of the LAMP stack, Linux is quite frequently used in other sectors as well [6]. How-ever, this adoption varies from country to country, on company size, and between sectors. For a mixed sample from industry and public sector, the use or planned use is reported to be as low as $17.7 \%$ in Sweden and as high as $43.7 \%$ in Germany [6]. Furthermore, numbers vary between about $10 \%$ and $75 \%$ for different strata [6]. A survey on Australia's top companies reports that $26 \%$ of the respondents used a varied spectrum of OSS products [8]. With the exception of Linux, Apache HTTP Server and perhaps a few others, most surveys report that less than $30 \%$ of the respondents have adopted OSS. Yet, little is known about the extent of the internal adoption of OSS in these companies.

In studies focusing on the software sector, $44 \%$ of the companies in a Finnish sample use OSS in their business [13] and in a study on Off-the-Shelf development, 44 or $38.3 \%$ of the 115 projects use OSS components [11]. Without being able to provide any numbers representative for the whole population, an Italian study found that software companies using OSS commonly adapt or build on top of these OSS products [1].

The transformation predicted by Fitzgerald involves company participation in the development of OSS products [4]. Companies are already known to be contributing by allowing employees spend their time at work participating in OSS projects [10]. Companies are among others involved in 97 of the 300 most active SourceForge projects [2]. However, this is most likely not representative for all of SourceForge's more than 170000 projects. A Swedish survey also found that several companies actively contribute to OSS projects [12].

We see that companies and organizations have adopted OSS and that they are involved in the development of OSS. There are however only a limited number of empirical findings which show the extent of this adoption and the demography of these companies. This paper will provide results which quantifies the adoption of OSS components in the Norwegian software industry.

${ }^{1}$ http://news.netcraft.com/ 


\section{Survey Method}

The purpose of the study was to investigate to what extent the Norwegian software industry approaches OSS development. As an expansion of [9], we carried out a nationwide survey to investigate this matter.

\subsection{Population: The Norwegian Software Industry}

Legal entities in Norway are registered in The Norwegian Central Coordinating Register for Legal Entities ${ }^{2}$ (CCRLE) with a Nomenclature Generale des Activites Economiques dans L'Union Europee (NACE) code. Based on 2005 data from CCRLE and other registers, Statistics Norway ${ }^{3}$ (SSB) reports that about 70000 employees, or $4.7 \%$ of all employees in Norway, are employed in the whole ICT sector [14]. In addition, the sector has a turnover of about $€ 22$ billion [14].

Table 1. The Norwegian 72.xx sector based on data from CCRLE 2007

\begin{tabular}{lll}
\hline Sub sector & NACE & Entities \\
\hline Computer and related activities & 72.00 & 26105 \\
\hline Hardware consultancy & 72.10 & 251 \\
Software consultancy and supply & 72.20 & 21559 \\
- Publishing of software (software houses: resale) & 72.21 & 1295 \\
- Other software consultancy and supply (single sale) & 72.22 & 20264 \\
Data processing & 72.30 & 489 \\
Database activities & 72.40 & 2916 \\
Maintenance \& repair: office, accounting and comp. machinery & 72.50 & 733 \\
Other computer related activities & 72.60 & 163 \\
\hline
\end{tabular}

The ICT sector in Norway includes telecommunication (64.20), ICT manufacture industry (32.xx), ICT wholesale and retail trade (51.8x), and the soft- and hardware sector (72.xx). Based on CCRLE data from 2007, we found that approximately 26 000 legal entities and 38500 employees constitute the soft- and hardware sector, see Table 1 . This gives an average company size of about 1.5 employees. According to SSB only about 13000 of these legal entities are active companies. More than $70 \%$ of these have less than one full time employee and about 1300 have five or more employees [14]. We will in this paper focus on the software sector $(72.2 \mathrm{x})$.

\footnotetext{
${ }^{2} \mathrm{http}: / /$ www.brreg.no/

${ }^{3}$ The Norwegian counterpart to the U.S. Census Bureau http://www.ssb.no/
} 


\subsection{The Sampling Process}

Data from CCRLE helped us constructing a close-to representative sample of software companies [3], with a focus on software (72.21) and consultancy (72.22) companies with more than five employees. However, the sample also included companies from the other 72.xx sub-sectors and companies with fewer than five employees. The purpose of the sampling process illustrated in Fig. 1 was twofold. First, estimate the share of companies integrating OSS components into their products. Second, create a sample for our survey consisting of companies using OSS components.

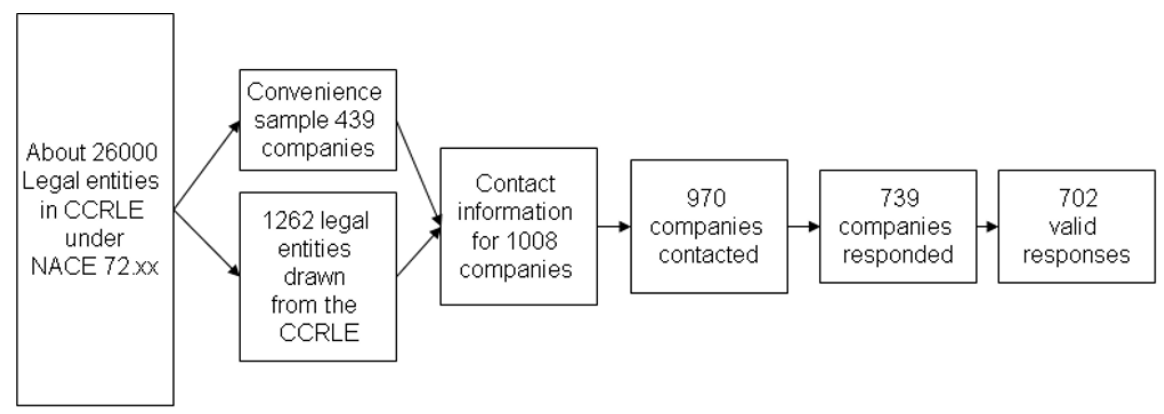

Fig. 1. The sampling process

Step 1: The sample was constructed based on a convenience sample of 439 companies and a stratified random sample of 1262 legal entities from CCRLE. The convenience sample was based on stratified random samples two from earlier studies and supplemented with companies from our knowledge and companies appearing in the media. The strata were defined according to the business organization form, the 72.xx sub-sectors, and the number of employees.

Step 2: Then, the two lists were merged. 300 duplicates entries were removed during this merger. Several companies occurred in both samples and some companies were registered with more than one legal entity, typically larger companies. We used data from CCRLE and the Internet to find web-sites and email addresses for the companies. Another 395 or $31.3 \%$ of the 1262 randomly selected legal entities were removed from the list because no contact information could be found. Knowing that only about $50 \%$ of the companies in the sector were active, this was not a surprise. The vast majority of these companies were small and most likely inactive companies. The final list contained contact information for 1008 companies from the Norwegian software industry.

Step 3: The screening process was carried out by sending the companies a brief request on email containing the questions stated below. About 200 of the companies from the convenience sample were contacted in March 2007 and the rest in June/July. One reminder was sent by email in September. The 200 companies 
contacted in March were only asked the first three questions while the remaining companies were asked all four questions.

1. How many employees do you have in Norway?

2. Are you doing software development in Norway?

3. Do you use open source components in your products or services (other than Linux, Apache HTTP Server, Eclipse, PHP/Perl, MySQL etc.)?

4. Do you participate in or run any open source projects?

38 of the 1008 email addresses did not work, leaving 970 companies. 201 of these companies came from the convenience sample, 555 from the stratified random sample, and 236 companies were included in both samples. 739 companies replied which give us a response rate of $73.3 \%$. 32 companies responded that their company was inactive or about to be dissolved, one company did not want to participate, and another four duplicate legal entities were found, leaving 702 or $69.6 \%$ valid responses. The response rates were similar across most of the different strata (size and sector). The names of the respondents and their email addresses were stored together with the other contact information.

Step 4: 569 or $81.1 \%$ of the 702 companies in our screening process confirmed that they perform software development. These companies make the basis for further analysis. The percentage of companies involved in software development is similar across different size and business types. However, when looking at sectors, the percentage varies from 73.6\% (72.40 Database activities) to $90.2 \%$ (72.20 Publishing of software).

\subsection{The Survey Process}

Close to $50 \%$ of the 569 companies constituting our sample integrate OSS components into their products. 204 of these companies were invited to participate in a web survey. The survey contained three parts focusing on (1) development of a commercial OSS product, (2) integration of OSS components into a software product, and (3) demographic information. The respondents should answer based on their experiences with the development of a typical software product containing OSS components. This product was selected by respondents and we had no control over this selection. To learn more about the companies and to increase the response rates, every second company ordered by size was contacted by phone. The companies were asked if they could participate and were sent an email with instructions if they accepted our invitation. The other half was invited to participate through email. One reminder was sent by email about a month later. 12 or $5.9 \%$ of the 204 companies could not or did not want to participate. Nevertheless, 95 of the 204 companies or $46.6 \%$ completed the survey. Of these 95, 21 were only involved in software development without directly developing software products, for instance consultancy companies providing developers to external customers. This left 74 or $36.3 \%$ valid responses for the two main parts. 


\section{Results}

This section presents results from both the screening process and from the survey.

\subsection{Selection and Integration of OSS Components}

Out of the 569 companies constituting our sample, 266 or $46.9 \%$ integrate OSS components into their software solutions. This use goes beyond merely using OSS operating systems, databases, infrastructure, development tools, and programming languages. The companies actually find, evaluate, and integrate OSS components into their software solutions. The integration of OSS components happens less frequently in software houses. Only $34.1 \%$ of the companies registered in sector 72.21, use OSS components in their products, see Table 2.

Table 2. Adoption of OSS components distributed over sectors

\begin{tabular}{|c|c|c|}
\hline Sector & Sample Size & OSS Adoption \\
\hline 72.21 Publishing of software & 129 & $34.1 \%$ \\
\hline 72.22 Other software consultancy and supply & 328 & $51.5 \%$ \\
\hline 72.30 Data processing & 18 & $38.9 \%$ \\
\hline 72.40 Database activities & 39 & $53.8 \%$ \\
\hline Other & 55 & $47.3 \%$ \\
\hline
\end{tabular}

From Table 3 we see that large companies integrate OSS components more often into their products than smaller companies. $56.9 \%$ of the companies with more than 100 employees use OSS and $50.0 \%$ of the companies with 25 to 99 employees integrate OSS components into their products compared to around $43 \%$ of the companies with between 2 and 24 employees. Companies with one or less than one full time employee, use OSS components somewhat more frequently.

Table 3. Adoption of OSS components distributed over the number of employees

\begin{tabular}{lll}
\hline Number of employees & \multicolumn{3}{l}{ Sample Size } & OSS Adoption \\
\hline 0 to 1 & 33 & $48.5 \%$ \\
2 to 4 & 61 & $42.6 \%$ \\
5 to 9 & 80 & $43.8 \%$ \\
10 to 24 & 189 & $43.9 \%$ \\
25 to 99 & 146 & $50.0 \%$ \\
More than 100 & 58 & $56.9 \%$ \\
\hline
\end{tabular}

66 companies completed the second part of the survey based on their experiences from the development of a software product containing OSS component. The products delivered by these companies serve all main business sectors with a small 
emphasis on the public and health sector. The functionality of these products was directed mainly towards web/portals and enterprise solutions. The respondents classified $40.9 \%$ of the products as domain specific and $36.4 \%$ as differentiating enduser products.

Even though OSS components can reduce the development effort substantially, they are in most cases integrated as part of a larger solution. In $72.7 \%$ of the products, OSS components provide less than $40 \%$ of the functionality of the end product. The number of OSS components is also kept low. $68.2 \%$ of the products contain less than six OSS components and $83.3 \%$ contain less than eleven OSS components. The effort spent developing these products during the last year, range from less than one (1) person-month to between 101 and 500 person-months.

\subsection{OSS Related Activities}

During the last year, $75.8 \%$ of the companies have developed between one and three software products containing OSS components. In one extreme case, one company had developed more than 50 products containing OSS components. In Part 3 of the survey, we requested the respondent to estimate how much of the company's income is generated by OSS related services or software development, see Table 4. Even though 41 of the 95 respondents answered less than $20 \%$ and 22 answered "don't know", 29 or $30.5 \%$ answered that more than $40 \%$ of their income comes from OSS related services or software.

Table 4. Income from OSS related services and software development

\begin{tabular}{ll}
\hline Income from OSS & Number of companies \\
\hline NA/Don't know & 22 \\
$0 \%$ & 8 \\
$1-20 \%$ & 33 \\
$21-40 \%$ & 3 \\
$41-60 \%$ & 7 \\
$61-80 \%$ & 9 \\
$81-99 \%$ & 6 \\
$100 \%$ & 7 \\
\hline
\end{tabular}

\subsection{Participation in OSS Projects}

In total 368 of the 569 companies developing software responded to the fourth screening question. 60 or $16.3 \%$ of the respondents said that employees in their company participated in OSS projects. This participation was in some cases part of their job and in other more a hobby. Another 18 or $4.9 \%$ of the 368 companies said they have their own OSS project. However, through the researchers' previous 
experience with some of these companies we would say that the OSS projects are only an important part of the business for a few of them.

30 of the 66 companies completing Part 2 of the survey answered that they interacted with or participated in OSS projects during the development of their product. This interaction and participation was in all but three cases not organized through the company but rather left up to the individual developer.

\section{Discussion}

The use of OSS in Norwegian software industry is significant. Close to $50 \%$ of the companies developing software have integrated OSS components into one or more of their products and more than $30 \%$ of the respondents to our survey get over $40 \%$ of their income from OSS related services or software. The use of OSS in software houses (72.21) living of the sales of software licenses is somewhat lower than in other software sectors. This could be caused by reciprocal OSS licenses (e.g. GPL) which requires derivate products to be released under the same license, thus removing the software houses profits from sales of licenses. Another conceivable explanation is that companies focusing on development of their own software products are involved in the development of fewer products per year than consulting companies serving several different customers.

The products developed by the respondents served all major business sectors and $77.3 \%$ of them were classified as domain specific or differentiating end-user products. Thus, we can conclude that OSS is used in vertical products targeting all business sectors.

We observed increasing OSS use in relation to increasing company size. However, Lundell et al. observed that companies with more than 250 employees seemed more conservative towards OSS adoption [12], Bonaccorsi et al. found that size does not favor OSS adoption [1], and Ghosh et al. found variations in the adoption of OSS over company size, countries, and sectors [6]. The relation between size and OSS adoption needs to be investigated in future research. However, we see two possible explanations for this increased use of OSS. First, small companies commonly focus on a limited number of customers and specialize on a small set of different technologies. Several such companies replied that they were not using OSS because they focused only on one not-OSS-compatible technology. While large companies, often serve many customers using several different technologies, including OSS. Second, large companies hire more people. Because they hire more people it is more likely that they employ people with prior experiences with OSS.

Comparing the results from this survey with other results is a bit complicated. First, the number of related studies is fairly limited. Second, while we focused on integration of OSS components, most studies include all kinds of OSS products. Third, other studies focus on other sectors than the software sector. The $46.9 \%$ adoption of OSS components in the software sector is therefore lower than some of the extreme results in $[5,6]$. If our survey had included all kinds of OSS, we suspect 
the percent-age of OSS users to be significantly higher. On the other hand, our results are in line with the results from [13] where $44 \%$ of the software companies used OSS in their business.

Generalization to other countries is made somewhat more difficult because of the variations found in other studies [6]. There are also factors which influence the adoption of OSS in the Norwegian software sector. While the effects of these factors must be further examined, we believe the size of the companies, influence the OSS adoption. Most software companies in Norway are small or medium sized. Many have relatively few and mostly domestic customers, and they have also chosen to focus on a limited set of technologies. In addition, the Norwegian government has the last years increased its focus on open standards and OSS through public reports and the establishment of a national centre of expertise of OSS. Furthermore, there seems to be a push in Norway towards increased use of agile methods. While using such methods it is important to get something up and running as fast as possible. This and the fact that the cost of personnel in Norway is quite high may encourage higher re-use of code and components, including OSS.

Industrial participation in OSS projects seems limited and managed on an individual level. Only $16 \%$ of the software companies confirm that they do participate in the development of one or more external OSS products. This number has however some uncertainty. First, 200 of the companies in the screening process were not asked whether they participated in any OSS projects. Second, there is some confusion about what participation is. Some companies answered "we do not participate but we report bugs and share occasional bug fixes" while others answered "we do participate with some bug reports and bug fixes". However, we interpreted both these statements as participation. Third, participation in OSS projects is in most cases managed on a personal level. Knowing what all other employees are doing is difficult if not impossible for the respondents in our screening process and the number of companies participating in OSS projects could therefore be higher.

The sample has an intentional bias towards companies with more than five employees. This bias was reinforced by the fact that we were unable to find contact in-formation for several small and probably inactive companies. The majority of companies without a web site are most likely inactive since nowadays the Web is considered the most important communication channel. To aid the sampling we benefited from CCRLE and the NACE sector codes. While this classification was of great help, the software industry is an industry with rapid and frequent changes. As a consequence of these changes, central registers such as CCREL are not up-to-date at all times. For example, only about $90 \%$ of the companies under 72.20 "Publishing of software" actually develop software.

Response rates of $73.3 \%$ for the screening process and $36.3 \%$ valid responses in the main survey is decent compared to many other studies but low response rates is one of the challenges with survey research. Even though there is room for improvement, we have been able to get responses from a large and close to representative sample of the Norwegian software industry. The research design is 
well documented and replicating the survey in another setting should be easy, though labor-intensive.

\section{Conclusion}

Results from our study show limited company involvement in the development of OSS products but widespread use of OSS components. By integrating OSS into vertical products serving all major business sectors, the software industry will contribute to wider adoption of OSS. The software industry has clearly started to adopt OSS products and contribute to the transformation of OSS into a commercially viable form. However, this transformation is far from completed.

The results presented here are currently followed up in several ways. In parallel to this survey, we have also approached OSS adoption through qualitative studies. Data from both the survey and these qualitative studies is currently being analyzed. Findings from these analyses will provide a basis for further research. This survey focuses on the Norwegian software sector, which is dominated by small and medium sized companies. The adoption of OSS may be different in other sectors and in other countries. We are therefore looking at the possibilities of conducting similar surveys in both other sectors and European countries. To understand the trend of OSS adoption, we are also considering a replication of the survey in Norway. Furthermore, the survey identified a few companies developing their own OSS products. We plan to follow up on these companies to try to understand if they manage to attract and sustain communities and how they interact with these communities.

\section{References}

1. Andrea Bonaccorsi, Silvia Giannangeli, and Cristina Rossi. Entry Strategies under Competing Standards: Hybrid Business Models in the Open Source Software Industry. Management Sci-ence, 52(7):1085-1098, July 2006.

2. Andrea Bonaccorsi, Dario Lorenzi, Monica Merito, and Cristina Rossi. Business Firms' Engage-ment in Community Projects. Empirical Evidence and Further Developments of the Research. In Proceedings of the First International Workshop on Emerging Trends in FLOSS Research and Development FLOSS'07, page 13, Minneapolis, US, 2007. IEEE Computer Society.

3. Reidar Conradi, Jingyue Li, Odd Petter N. Slyngstad, Vigdis By Kampenes, Christian Bunse, Maurizio Morisio, and Marco Torchiano. Reflections on Conducting an International Survey of Software Engineering. In June Verner and Guilherme H. Travassos, editors, Proceedings on In-ternational Symposium on Empirical Software Engineering ISESE'05, pages 214-223, Brisbane, Australia, 2005.

4. Brian Fitzgerald. The Transformation of Open Source Software. MIS Quarterly, 30(3), 2006. 
5. Rishab Aiyer Ghosh. Study on the Economic Impact of Open Source Software on Innovation and the Competiveness of the Information and Communication Technologies (ICT) Sector in the EU. Technical report, UNU-MERIT, 2006.

6. Rishab Aiyer Ghosh, Gregorio Robles, and Ruediger Glott. Free Libre and Open Source Soft-ware: Survey and Study. Technical report, International Institute of Infonomics, University of Maastricht, 2002.

7. Eugene Glynn, Brian Fitzgerald, and Chris Exton. Commercial Adoption of Open Source Soft-ware: An Empirical Study. In Proceedings of International Conference on Empirical Software Engineering, pages 225-234, Noosa Heads, Australia, 2005.

8. Sigi Goode. Something for Nothing: Management Rejection of Open Source Software in Austra-lia's Top Firms. Information \& Management, 42(5):669-681, 2005.

9. Ø $\varnothing$ yvind Hauge, Carl-Fredrik Sørensen, and Andreas Røsdal. Surveying Industrial Roles in Open Source Software Development. In Joseph Feller, Brian Fitzgerald, Walt Scacchi, and Alberto Sillitti, editors, Proceedings on the Third International Conference on Open Source Systems, pages 259-264, Limerick, Ireland, 2007. Springer.

10. Karim R. Lakhani and Robert G. Wolf. Why Hackers Do What They Do: Understanding Moti-vations and Effort in Free/Open Source Software Projects. In Joseph Feller, Brian Fitzgerald, Scott A. Hissam, and Karim R. Lakhani, editors, Perspectives on Free and Open Source Soft-ware, pages 3-23. MIT Press, 2005.

11. Jingyue Li, Reidar Conradi, Odd Petter N. Slyngstad, Christian Bunse, Umair Khan, Marco Torchiano, and Maurizio Morisio. An Empirical Study on Off-the-Shelf Component Usage in Industrial Projects. In Frank Bomarius and Seija Komi-Sirvio, editors, Proceedings of the 6th In-ternational Conference on Product Focused Software Process Improvement PROFES'2005, pages 54-68. Springer, 2005.

12.Björn Lundell, Brian Lings, and Edvin Lindqvist. Perceptions and Uptake of Open Source in Swedish Organisations. In Ernesto Damiani, Brian Fitzgerald, Walt Scacchi, Marco Scotto, and Giancarlo Succi, editors, Proceedings of The Second International Conference on Open Source Systems, pages 155-163, Como, Italy, 2006. Springer.

13.Uolevi Nikula and Sami Jantunen. Quantifying the Interest in Open Source System: Case South-East Finland. In Marco Scotto and Giancarlo Succi, editors, OSS 2005: Proceedings of the First International Conference on Open Source Systems, 11-15 July 2005, Genova, Italy, pages 192-195, 2005.

14.SSB. StatBank Norway, 2007. http://statbank.ssb.no/statistikkbanken/, accessed 2007-0801 .

15. Mikko Välimäki, Ville Oksanen, and Juha Laine. An Empirical Look at the Problems of Open Source Adoption in Finnish Municipalities. In Proceedings of the 7th International Conference on Electronic Commerce ICEC'05, pages 514-520, Xi'an, China, 2005. ACM.

16. Shahron van Rooij. Open Source software in US higher education: Reality or illusion? Educa-tion and Information Technologies, 12(4):191-209, December 2007.

17. Teresa Waring and Philip Maddocks. Open Source Software implementation in the UK public sector: Evidence from the field and implications for the future. International Journal of Informa-tion Management, 25(5):411-428, October 2005.

18. David A. Wheeler. Why Open Source Software / Free Software (OSS/FS, FLOSS, or FOSS)? Look at the Numbers!. http://www.dwheeler.com/oss_fs_why.html, accessed 2007-12-09. 